\title{
ESTUDO DO CONTEXTO ARQUEOLÓGICO DO SÍTIO ARQUEOLÓGICO ALVIM, MUNICÍPIO DE PIRAPOZINHO, SP
}

\author{
Gustavo de Jesus Andrade, Neide Barrocá Faccio \\ Universidade Estadual Paulista "Júlio de Mesquita Filho" - UNESP, Curso de Geografia, Presidente Prudente, SP. E- \\ mail: gustavo.andrade.fct@gmail.com. Agência de fomento: Fundação de Amparo a Pesquisa no Estado de São Paulo \\ (FAPESP)
}

\section{RESUMO}

Apresenta-se os resultados da análise de 1.210 artefatos lascados do Sítio Arqueológico Alvim, localizado no Município de Pirapozinho, SP, na área do Baixo Vale do Rio Paranapanema, lado paulista, este estudo constitui-se em um importante elemento para a compreensão das ocupações de grupos caçadores-coletores dessa região. Para tanto, estão sendo realizados estudos da tecnologia de produção de tais artefatos. Essa abordagem enfoca a cadeia operatória de produção, analisando todo o processo de produção do objeto, desde a coleta da matéria--prima até o descarte do instrumento, permitindo caracterizar a tecnologia de produção do lítico lascado do Sítio Arqueológico Alvim.

Palavras-chave: Cadeia operatória, caçador-coletor, tecnologia lítica.

\section{STUDY OF THE ARCHAEOLOGICAL CONTEXT OF THE ARCHAEOLOGICAL SITE ALVIM, MUNICIPALITY OF PIRAPOZINHO, SP.}

\begin{abstract}
We present the results of the analysis of 1210 materials líticos chipped of the Archaeological Site Alvim, locatedin the Local authority of Pirapozinho, SP, in the area of the Low Valley of the Rio Paranapanema, São Paulo side, this study is based on important element for the understanding of the occupation of the native hunters-collectors. For so much there Are being realization studies of the technology of production of such products. This approach focus the operating chain of production, analyzing the whole process of production of the object, from the collection from the raw material even discard it of the instrument. allowing to characterize the production technology of the chipped lytic of the Alvim Archaeological Site.
\end{abstract}

Keywords: Production chain, hunters-collectors, technology lytic. 


\section{INTRODUÇÃO}

O Sítio Arqueológico Alvim apresenta a maior coleção de peças lítico lascadas (Figura 1), se comparada com os demais sítios da área do Baixo Vale do Rio Paranapanema, lado paulista. Os líticos desse sítio foram estudados, parcialmente, por Faccio (1992) e careceu de estudos com a abordagem tecnológica, de reconstituição da(s) cadeia(s) operatória(s) de produção, o que propomos neste artigo.

Figura 1. área de localização do Sítio Arqueológico Alvim no Baixo vale do Rio Paranapanema

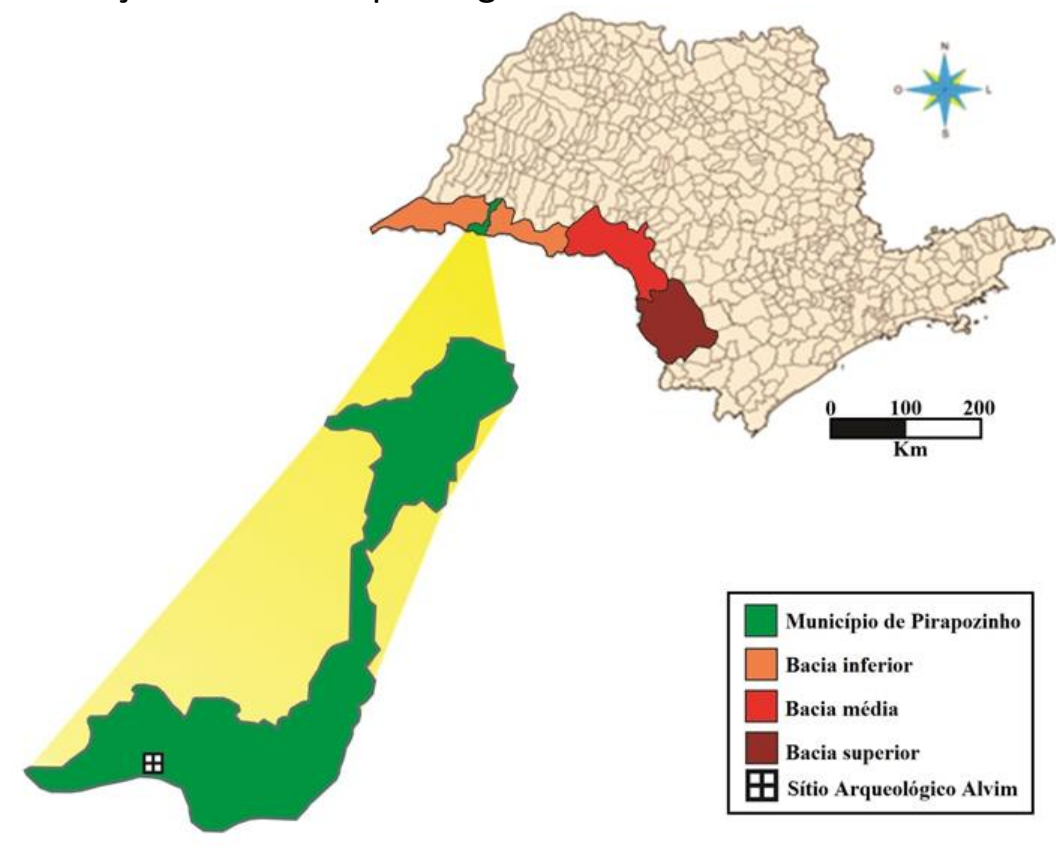

Fonte: Morais (1995). Adaptado pelo autor.

O objetivo desse trabalho é contribuir com informações sobre o Sistema Regional de Ocupação Indígena da área do Rio Paranapanema, objeto de estudo do ProjPar (Projeto Paranapanemoa). Segundo Morais (1992),

- Projeto Paranapanema é um programa regional de pesquisas arqueológicas que tem por objetivo o estudo das sociedades indígenas no trecho paulista da bacia do Rio Paranapanema por meio de objetos produzidos por elas. Tais objetos, principalmente utensílios de pedra lascada, pedra polida, vasilhas e fragmentos de cerâmica, são recuperados nos sítios arqueológicos descobertos na região (MORAIS, 1992, p.1).

\section{METODOLOGIA}

Neste trabalho, buscamos a análise tecnológica de reconstituição das cadeias operatórias de produção das peças líticas do Sítio Arqueológico Alvim. Acreditamos que, com essa abordagem teórico-metodológica, é possível obter importantes informações acerca das características de sítios caçador-coletor da região em estudo e, dessa forma, é possível acrescentar um quadro mais amplo de informações a respeito do Sistema de Ocupação Regional do Vale do Paranapanema.

Partindo desse pensamento, ressaltamos que Mauss, o percursor do conceito de cadeia operatória de produção, tema importante para a análise da indústria lítica do Sítio Arqueológico Alvim, afirma que "todos os objetos devem ser estudados: 1ㅇ em si mesmos; 2으 em relação às pessoas que deles se serviram; 3o em relação à totalidade do sistema observado" (MAUSS, 1972, p. 37).

Dessa forma, é possível determinar que a tecnologia lítica está ligada a fatores humanos e naturais. Os fatores humanos são: o espaço habitado, a cultura/tradição do grupo e a própria 
individualidade do artesão que produziu o instrumento (FOGAÇA, 2001). Já os fatores naturais estão ligados, de maneira geral, à disponibilidade de matéria-prima, à localização das jazidas e às propriedades físicas do material, na medida em que a matéria-prima apresenta as especificidades necessárias para os trabalhos que serão aplicados e, então, poderá ser explorada com maior ou menor frequência (ALVES, 2013).

Grace (1996) refere-se à sequência operatória como constituinte dos diferentes estágios da produção de ferramentas, desde o momento da aquisição da matéria-prima, até o descarte final das peças que não terão mais utilidade ou foram muito desgastadas, com ênfase nos materiais coletados. $\mathrm{O}$ autor ainda aborda que as etapas de produção e a análise metodológica dos materiais líticos ou cerâmicos com a perspectiva do conceito de cadeia operatória, permitem compreender o comportamento humano complexo.

Grace elaborou uma descrição detalhada da cadeia operatória da indústria lítica (Figura 2)

Figura 2. Cadeia operatória de produção de lítico lascado

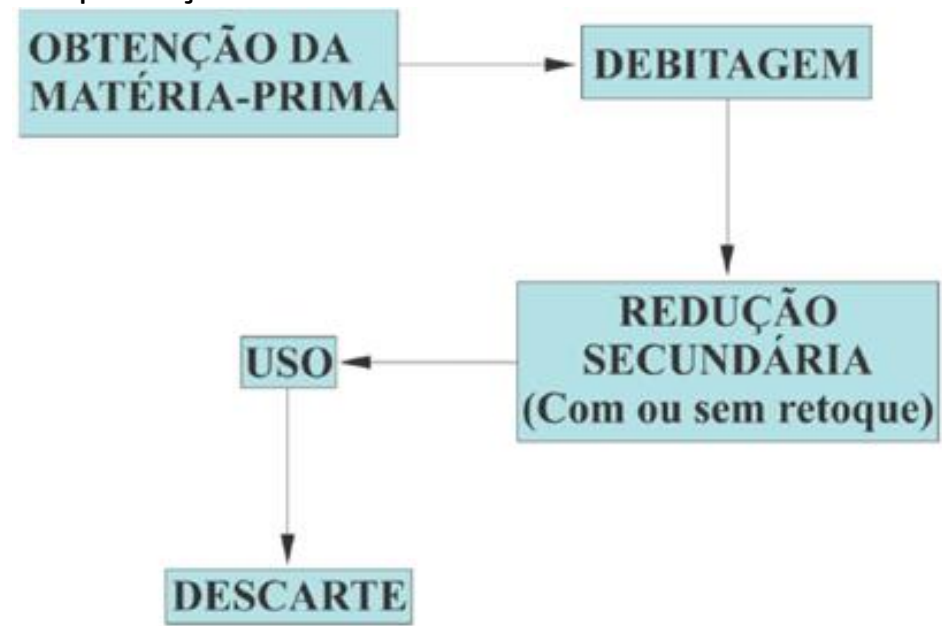

Fonte: Grace (1996).

Para Chazan (2005), o conceito de cadeia operatória está inserido no estudo da Arqueologia dos Gestos, pois, quando um artesão faz uma pausa para planejar suas ações iniciais ou para dar continuidade na produção do material, é importante questionar o que ele pensa. Essa é uma pergunta que arqueólogos podem, pelo menos, aspirar a responder. Uma Arqueologia do Gesto está interessada na conexão entre pensamento e ação (CHAZAN, 2005).

\section{RESULTADOS}

Partindo da análise das peças sob o conceito de reconstrução de uma cadeia operatória foi possível identificar que pontas de projétil não são iguais e variam de uma região para outra. Podese citar aqui, como exemplo, a morfologia de pontas de projétil definidas como "rabo de peixe" (Foto 1) que, segundo dados apresentados por Loponte, Okamura e Carbonera (2016), estão associados à Tradição Umbu. 
Foto 1. Pontas de projétil "Rabo de Peixe" associadas a Tradição Umbu

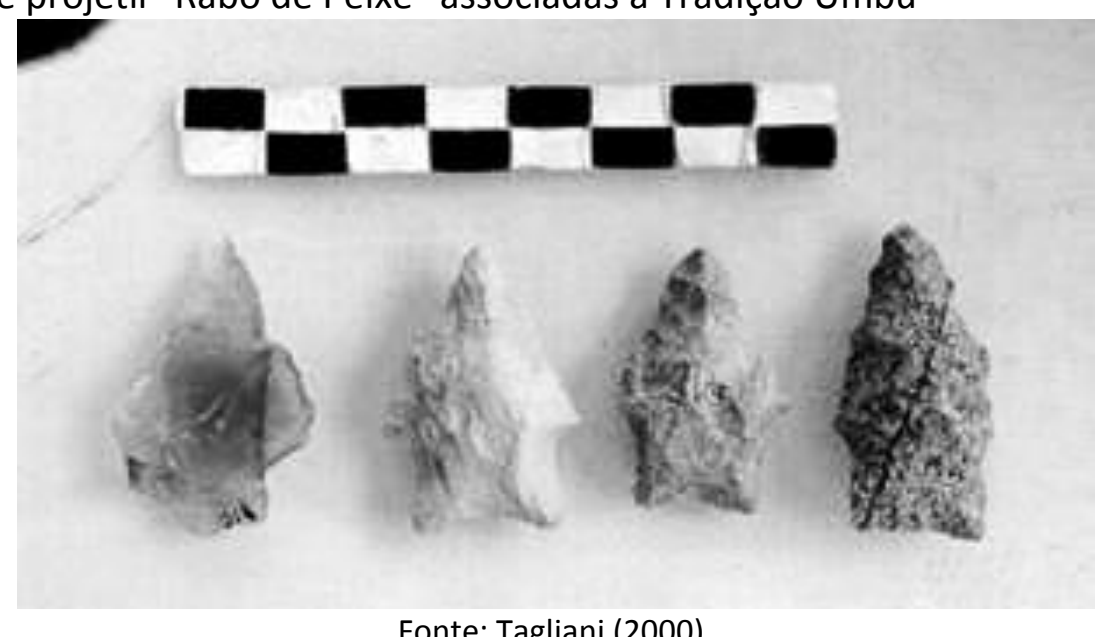

Fonte: Tagliani (2000).

A foto 2 apresenta quatro pontas de projétil encontradas na área do Sítio Arqueológico Alvim, que, da mesma forma que as pontas de flechas apresentadas por Araújo e Okomura (2017), também possuem pedúnculo; porém é possível identificar a morfologia divergente entre o material apresentado na foto 1 com as pontas de projétil expostos na foto 2 .

Foto 2. Pontas de projéteis evidenciados no Sítio Arqueológico Alvim

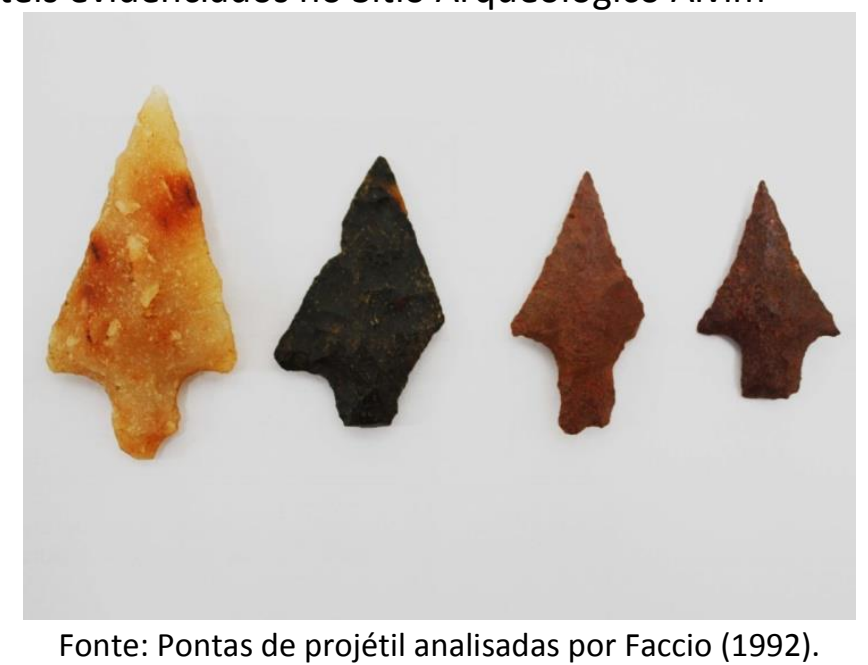

Diante do exposto, o grupo pré-colonial que ocupou a área hoje denominada Sítio Alvim será tratado como de caçadores-coletores, não sendo utilizada a denominação da "Tradição Umbu" para esse grupo.

Como observado na foto 2 , dos quatro exemplares de pontas de projétil evidenciados no Sítio Arqueológico Alvim e analisados, um é confeccionado em quartzito, silexito e os outros dois em arenito silicificado. Concordamos com Alves (2013), quando escreve que o reconhecimento de uma matéria-prima adequada para determinado tipo de serviço, está ligada a sucessivos testes experimentais. Trata-se, assim, da relação do homem pré-histórico com o meio físico. Desse modo, conforme o artesão vai conhecendo o meio em que vive, pode explorá-lo com maior eficiência. No caso do contexto de sítios arqueológicos, localizados na região do Rio Paranapanema, a matéria-prima utilizada para a confecção de materiais líticos lascados de maior ocorrência é o arenito silicificado.

Estudar a cadeia operatória de produção dos líticos lascados do Sítio Arqueológico Alvim tornou-se importante para que se pudesse compreender os 1210 artefatos evidenciadas no sítio como um todo, desde a forma de confecção até a origem de lascas, instrumentos, resíduos, 
estilhas e outras peças. Para a construção da cadeia operatória foi necessário o estabelecimento da analise dos materiais arqueológicos (de acordo com a tabela 1).

Tabela 1. análise dos 1210 artefatos líticos.

\begin{tabular}{|c|c|c|c|c|c|}
\hline Categoria & Frequência & Suporte & Frequência & Materia-Prima & Frequência \\
\hline Instrumento & 151 & Seixo & 1060 & Arenito Silicificado & 538 \\
\hline Lasca & 540 & Bloco & 70 & Silexito & 523 \\
\hline Núcleo & 385 & Cristal & 34 & Silexito / Quartzito & 24 \\
\hline $\begin{array}{l}\text { Fragmento de } \\
\text { Instrumento }\end{array}$ & 7 & Plaqueta & 22 & Quartzito & 30 \\
\hline Residuo & 89 & Nódulo & 24 & Basalto & 69 \\
\hline Seixo & 19 & & & Arenito & 26 \\
\hline Plaqueta & 9 & & & & \\
\hline Estilha & 1 & & & & \\
\hline Percutor & 9 & & & & \\
\hline
\end{tabular}

Fonte: $\mathrm{O}$ autor.

De acordo com a análise da Tabela 1 é possível notar uma maior frequência de Lascas, que são materiais de uso momentâneo e descartadas, seguido de núcleos de onde lascas, fragmentos de instrumentos, estilha e instrumentos foram confeccionados. Como suporte, blocos e seixos pela proximidade de rios e córregos são os mais utilizados. O Arenito Silicificado e o Silex são as matérias-primas mais utilizadas pela qualidade da matéria-prima em construir artefatos como lascas e instrumentos com gume cortante.

\section{DISCUSSÃO}

As pontas de flecha associadas ao Grupo caçador-coletor do Sítio Arqueológico Alvim (Foto 2), durante muitos anos estiveram associadas à Tradição Umbu, porém, de acordo com Pivetta (2012), diversos grupos caçadores-coletores são associados à Tradição Umbu pela proximidade das dimensões das pontas de projétil.

De acordo com Schmitz (1987), há dois problemas no uso do termo Tradição Umbu, sendo eles: a extensa distribuição geográfica dos sítios e o enorme período de tempo datadas das ocupações. A manutenção dessa tradição implicaria grupos humanos espalhados por áreas muito grandes durante um enorme período, sem novas formas de adaptação dos materiais. Outro fator complicador seria a escassez de indicadores cronológicos identificados nessa Tradição.

Dessa forma, é possível inferir que as pontas de projétil de Rio Claro - SP analisadas por Araújo e Okumura (2016) e que, inicialmente, foram caracterizadas como sendo da Tradição Umbu, têm o pedúnculo - cabo ou haste situada no lado oposto ao da superfície cortante, sendo maior e mais afilado em comparação aos projéteis "rabo de peixe", com contornos similares aos da letra V: já os projéteis localizados nas regiões do Rio Grande do Sul, Santa Catarina, Argentina e Uruguai possuem pedúnculos bifurcados, que se assemelham a um rabo de peixe.

Sendo assim, é possível compreender que Schmitz (1987), Araújo e Okumura (2017) constatam que a Tradição Umbu não poderia dissipar-se para diversas regiões da America do Sul, sem que as características culturais, tanto materiais, quanto imateriais sofressem alterações.

Vale cuprir aqui o conceito de paisagem para compreendimento do sistema de ocupação no Baixo Vale do Rio Paranapanema.

Dessa forma a abordagem da Arqueologia da Paisagem busca identificar elementos que contribuam para determinantes culturais, visto que há outras necessidades pertinentes a 
sobrevivência e a alimentação, a obtenção de matérias-primas e, recursos naturais que garantam o desenvolvimento tecnológico e necessidades habitacionais.

De acordo com Ashmore e Knapp (1999), o ambiente manifesta-se como paisagem, apenas quando as pessoas criam e vivenciam espaços como um complexo de lugares. $O$ senso de lugar das pessoas e seu envolvimento com o mundo em volta delas são, invariavelmente, dependentes de sua própria situação social, cultural e histórica.

Lembramos aqui então que a análise da tecnologia de produção dessas peças foi constituída, ao passo que nossa pretensão é reconstituir a cadeia-operatória de produção das peças lítico-lascadas dos homens pré-coloniais que lascaram e utilizaram essas peças em regiões do Vale do Rio Paranapanema.

Dessa forma em síntese, trabalho constituiu uma revisão da literatura pesquisada sobre teoria e metodologia que guiou nossas ações para o cumprimento do objetivo de estudar a tecnologia das coleções lítico lascadas do Sítio Arqueológico Alvim e caracterizar seu grupo de ocupação.

\section{CONCLUSÃO}

A partir dos dados apresentados neste trabalho, foi possível concluir que os materiais líticos lascados do Sítio Arqueológico Alvim, não são resultantes da Tradição Umbu, de acordo com algumas correntes metodológicas na área de pesquisa da Arqueologia Contemporânea; mesmo que outras atribuam os materiais à Tradição, pesquisas recentes refutam tal afirmação. A partir desse pressuposto, nesta pesquisa o sítio será tratado como um sítio caçador-coletor (em datação anterior à ocupação guarani e jesuítica).

As datações estipulam ocupações de aproximadamente 1.500 anos para os sítios litocerâmicos e 7.000 anos para os primeiros sítios líticos, provavelmente, ocupações de grupos nômades caçadores-coletores. Dessa forma, há uma margem temporal significativa entre uma ocupação e outra.

Vale ressaltar a importância de diversas pesquisas que foram realizadas na região do Paranapanema paulista, desde as primeiras escavações coordenadas por Luciana Pallestrini até a criação do Projeto Paranapanema. Inúmeros sítios arqueológicos foram evidenciados e pesquisados nesse período, (dentre eles o Sítio Arqueológico Alvim) que vai de 1968 (data das primeiras escavações) até os dias atuais. Porém, ainda há muito que fazer, uma vez que existem muitos outros sítios, nas margens do rio Paranapanema, para serem escavados e analisados, assim como muitas coleções para serem analisadas e comparadas. E também seriam inseridos outros sítios arqueológicos em regiões próximas à margem do Paranapanema ao contexto regional de ocupação, já que muitas culturas não se fixavam em um determinado território de forma permanente.

\section{REFERÊNCIAS}

ALVES, A, A apropriação dos recursos naturais por grupos pré-históricos no baixo vale do Rio Paranapanema paulista: o estudo do Sítio Arqueológico Lagoa Seca, lepê, SP, Monografia (Bacharelado em Geografia), Faculdade de Ciências e Tecnologia, Universidade Estadual Paulista "Júlio de Mesquita Filho", Presidente Prudente,SP 2013.

ARAÚJO, A; OKUMURA M. Pesquisa Fapesp. Pontas pré-históricas de São Paulo são diferentes dos artefatos sulinos. Youtube. 18. Jun. 2012. Disponível em: <youtube.com/watch?v=2ekRLnLgrv8\&feature=youtu.be>. Acessado em: 17. Maio. 2017.

ASHMOR, W.; Knapp, A. Arqueologies of Landscape: contemporary perspectives. Black Well, Malden; Mass. 1999. 
CARBONERA, M; OKAMURA, M; LOPONTE, D. New records of fishtail projectile points from Brazil and its implications for its peopling Journal of Lithic Studies vol. 3, no1, p. 63-85. 2016.

CHAZAN, M. Towards an Archaeology of Gesture. Department of Anthropology, University of Toronto (2005).

FACCIO, N. B. Estudo do Sítio Arqueológico Alvim no contexto do Projeto Paranapanema. Dissertação (Mestrado em Antropologia Social). São Paulo: FFLCH/USP, 1992.

Arqueologia Guarani na área do Projeto Paranapanema: estudo dos sítios de lepê, SP. Volume I. Tese (Livre Docência em Arqueologia) - Museu de Arqueologia e Etnografia, Programa de Pós-Graduação em Arqueologia - Universidade de São Paulo, São Paulo, 2011.

FOGAÇA, E. Mãos para o pensamento: a variabilidade tecnológica de indústrias líticas de caçadores-coletores holocênicos a partir de um estudo de caso: as camadasVIII e VII da Lapa do Boquete (Minas Gerais, Brasil - 12.000/10.5000 B.P) 2001. 452f. Tese Pontifícia Universidade Católica do Rio Grande do Sul, Porto Alegre.

GRACE, R. O enfoque "châine opératoire" para análises líticas. 1996.

LUZ, J. A. R. Estudos da Tecnologia das Peças Líticas Lascadas no Vale do Rio Paranapanema: Sítios Arqueológicos Vallone e Gurucaia, Dissertação (Mestrado em Arqueologia) Universidade de São Paulo, Museu de Arqueologia e Etnologia, São Paulo, 2010.

MORAIS, J. L.. Plano Cartográfico do Projeto Paranapanema. Revista do Museu de Arqueologia e Etnologia, São Paulo, v. 2, p. 155-157, 1992, https://doi.org/10.11606/issn.24481750.revmae.1992.109005.

. Salvamento arqueológico na área de influência da PCH Moji-Guaçu. Revista do Museu de Arqueologia e Etnologia, MAE-USP, São Paulo, 5 : 1995, 77-98.

A ocupação do espaço em função do relevo e o aproveitamento das reservas petrográficas por populações pré-históricas do Paranapanema, SP. Coleção Museu Paulista, série de arqueologia, vol. 6, Editora do Fundo de Pesquisas do Museu Paulista da USP, São Paulo, 1979, $83 \mathrm{p}$.

PIVETTA, M. Pontas de Um Passado Remoto. Pesquisa FAPESP, V.1 № 194, p.82-85. 2012.

SCHMITZ, P. I. Prehistoric hunters and gatherers of Brazil. Journal of World Prehistory 1 (1): 53126, 1987, https://doi.org/10.1007/BF00974817.

TAGLIANI, P. R. A. Arqueologia, história e socioeconomia da restinga da Lagoa dos Patos: uma contribuição para o conhecimento e manejo da reserva da biosfera. Rio Grande: Fundação Universidade Federal do Rio Grande - FURG. 2000. 257 p.b 